\title{
Effect of Road Profile on Suspension System of Heavy Truck
}

\author{
Salem F. Salman \\ Material Engineering Department, University of Diyala, 32001Diyala, Iraq \\ Email address: $\underline{\text { dr_alizi@yahoo.com }}$
}

\begin{abstract}
All vehicles are affected by the type of the road they are moving on it. Therefore the stability depends mainly on the amount of vibrations and steering system, which in turn depend on two main factors: the first is on the road type, which specifies the amount of vibrations arising from the movement of the wheels above it, and the second on is the type of the used suspension system, and how the parts connect with each other. As well as the damping factors, the tires type, and the used sprungs. In the current study, we will examine the effect of the road roughness on the performance coefficients (speed, displacement, and acceleration) of the joint points by using a BOGE device.
\end{abstract}

Keywords: Dynamic load; Suspension system; Vibration

Paper History: (Received: 9/12/2018; Accepted: 19/2/2019)

\section{INTRODUCTION}

When a car travel with high speed, a range of unwanted movements appear as vibrations. Thesee phenomena are transmitted to passengers either by tactile , visual, or aural paths . Ride is a term used to express the tactile and visual vibrations, while noise refer to aural vibration. Alternately, the spectrum of vibrations may be divided into two categories, ride $(0-25 \mathrm{~Hz})$ and noise $(25$ $20,000 \mathrm{~Hz}$ ) [1]. It is difficult to consider each type of vibration separately ,because they are so correlating.The vibration medium is one of the more standard by which passengers rating the design quality of vehicle. The vehicle is a dynamic system , but only exhibits vibration in response to excitation input. Vehicle ride vibration may be excited in many sources. Thesee sources are divided to two classes , level of road profile and on-board sources ". Road roughness depends on a combinations of factors ,e.g., potholes due to bad road paving, and failure to adopt the standard system when constructing the road
The 1/4-vehical revel a pattern of a $1 / 4$ of a four wheeled vehicle. A $1 / 4$ car models contain a sprung mass propped on a suspension system which has stiffness and damping specific. The suspension system is linked to the un sprung mass of the axle. Quarter - car shown in Fig.(1) which is always applied on suspension analysis [1]. Thee equation of motions for quarter car pattern is obtained by adding vertical forces on the sprung and un sprung masses which is often used for suspension analysis.

\section{RELATIONSHIP BETWEEN ROAD PROFILE AND WHEEL TRAVEL}

Bump under thee tire at time $t$ is $\mathbf{y}_{\text {road }}(t)$, The rate of change in the level of high road bump, $\mathrm{y}_{\text {road }}(t)$, acts as a velocity and acceleration input to the wheel of the tire .The vehicle tire is modeled as a sprung and shock absorber $\mathrm{Kt}, \mathrm{Bt}$, between the road and the un sprung mass. The suspension system of the car is modeled as a supplemental sprung and shock absorber ,Ks, Bs between the un sprung and sprung masses. Vu and Vs are respectively the Vertical velocities of the un sprung and sprung masses. Du and Ds are sprung and un sprung compression distances. The dynamic behavior of a vehicle can be described by considering the relationship between input and output. Inputs are a major source of excitement between the wheel of the vehicle and the road , or combinations there under. The output will be the vibrations on the body. Gain represents the ratio between output and input amplitude for the dynamic system. The ratio may be one of forces, displacements, velocities or accelerations [1] .Table (1) shows the scale for present serviceability rating (PSR) and approximate international road roughness index of road First for all we assumption that the road is an infinite cam with the way profile of mixed harmonic sine waves and the wheel as a follower having vertical movement only[8] (Fig. 1) .

Table 1. International road roughness index

\begin{tabular}{|c|c|c|}
\hline PSR. & Road Quality & $\begin{array}{l}\text { IRI m/km or } \\
\mathrm{Mm} / \mathrm{m}\end{array}$ \\
\hline Less than1 & V. poor & More than6 \\
\hline $1-2$ & Poor & $6-3,5$ \\
\hline $2-3$ & Fair & $3,5-2$ \\
\hline $3-4$ & Good & $2-0.9$ \\
\hline $4-5$ & V. good & 0,9 to 0 \\
\hline
\end{tabular}

IRI was firstly founded and initiated by the world bank through an IRI. The international road roughness is defined as property of true profile, which summarizes the roughness qualities that impact vehicle response. The response can be mathematically described with a relatively simple set of dynamic equations known's as a $1 / 4$ car simulation as shown in fig. (2) . The IRI used to 
define characteristic of the longitudinal profile of a travelled.

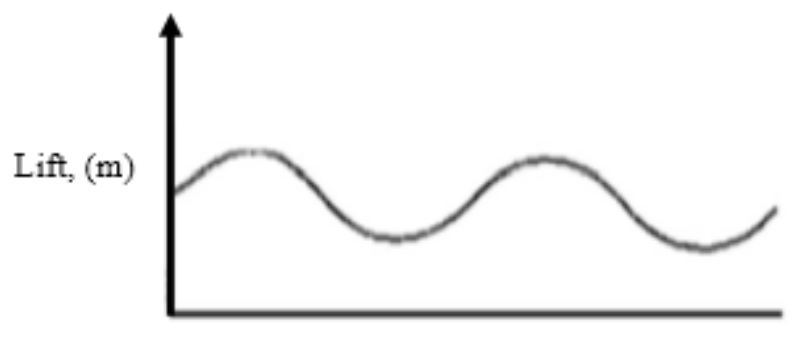

Traveling distance /m

Figure 1. $\mathrm{Y}$ axis $=\mathrm{Lift}(\mathrm{m}), \mathrm{X}$ axis=distance on the road $(\mathrm{m}) \mathrm{m}$

\section{Mathematical Model}

The $1 / 4$ car pattern suspension take into consideration the conventional inertia force due to the sprung mass Ms, which is one-quarter the mass of vehicle body, and with the displacement $\mathrm{Xs}$, and an un sprung mass, $\mathrm{M}$ us, which is mass of a single wheel and attached suspension component. Thee dynamic behavior for thee complete $1 / 4$ car model in steady-state. Vibration can be obtained by writing Newton's Second Law for the sprung and un sprung masses. By considering a free F,B,D, foe each , the following differential equations are obtained for the sprung and un sprung masses, resp.

$\mathrm{M} \hat{\mathrm{z}}+\mathrm{C}_{\mathrm{s}} \dot{\mathrm{z}}+\mathrm{K}_{\mathrm{s}} \mathrm{Z}=\mathrm{C}_{\mathrm{s}} \dot{\mathrm{z}}_{\mathrm{u}}+\mathrm{K}_{\mathrm{s}} \mathrm{Z}_{\mathrm{u}}+\mathrm{F}_{\mathrm{b}}$

(1) $\mathrm{M} \hat{\mathrm{Z}}_{\mathrm{u}}+\mathrm{C}_{\mathrm{s}} \dot{\mathrm{Z}}_{\mathrm{u}}+\left(\mathrm{K}_{\mathrm{s}}+\mathrm{K}_{\mathrm{t}}\right) \mathrm{Z}_{\mathrm{u}}=\mathrm{C}_{\mathrm{s}} \dot{\mathrm{Z}}+\mathrm{K}_{\mathrm{s}} \mathrm{Z}+\mathrm{K}_{\mathrm{t}} \mathrm{Z}_{\mathrm{r}}+\mathrm{F}_{\mathrm{w}}$

(2)

where: Z- Sprung mass displacement . Zu- un sprung mass displacement. $Z_{r}-$ Road displacement. $F_{b}-$ Force on the sprung mass. $\mathrm{F}_{\mathrm{w}}$ - Force on the un sprung mass $. \mathrm{K}_{\mathrm{s}}-$ suspension stiffness. $\mathrm{K}_{\mathrm{t}}$ Tire stiffness. $\mathrm{X}=\mathrm{m} / \mathrm{M}$ Ratio of un sprung to sprung mass $C=\mathrm{C}_{\mathrm{s}} / \mathrm{M} . \mathrm{K}_{1}=\mathrm{K}_{\mathrm{t}} / \mathrm{M} . \mathrm{K}_{2}=\mathrm{K}_{\mathrm{s}} / \mathrm{M}$

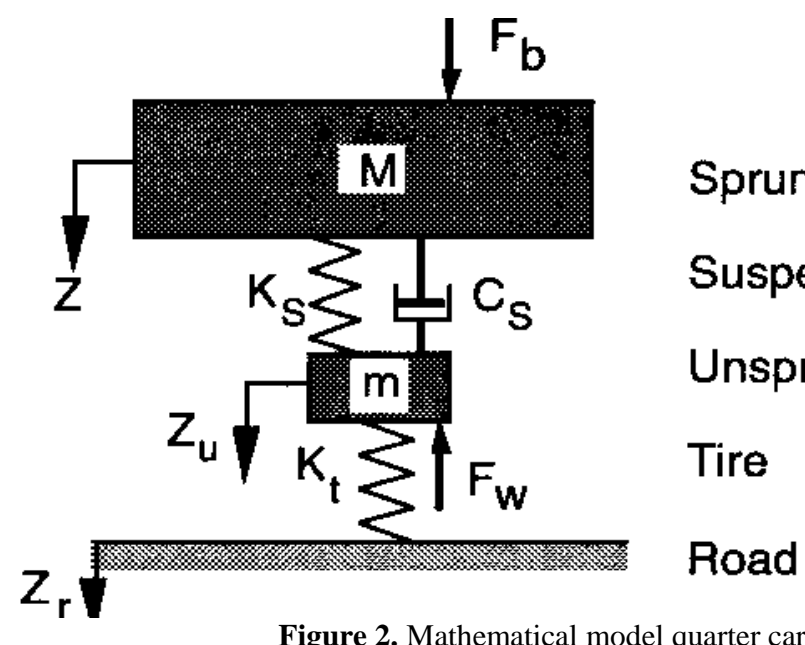

Figure (2) shows quarter car with two-degree of freedom system considered for analysis [1]. It's containing a sprung mass, Ms points out to part of car that is supported on sprung and un sprung mass which refers to the mass of vehicle wheel assembly. The Tire has been replaced with its equivalent stiffness and tire damping. Assuming the road profile boarded by sine wave of amplitude $=0.012 \mathrm{~m}$, and long of the wave $=15 \mathrm{~m}$ then the natural frequency is , $\omega=\sqrt{g} / \delta=\sqrt{ }(\mathrm{g} / \mathrm{static}$ deflection) $=8.6 \mathrm{rad} / \mathrm{s}$, since the $\mathrm{f}_{\mathrm{d}}=1,384 \mathrm{HZ}$ or cycles $/ \mathrm{s}$. If we taking damping factor, $\zeta=0.35$, then the amplitude due the road disturbance $=X\left[\sqrt{ }\left\{1+\left(2 \zeta \omega / \omega_{n}\right)^{2}\right\} \div\left[\left\{1-\left(\omega / \omega_{n}\right)^{2}\right\}^{2}+(2\right.\right.$ $\left.\left.\left.\left.\zeta \omega / \omega_{\mathrm{n}}\right)^{2}\right\}\right]\right]=12.5 \mathrm{~mm}$. The amplitude changes from $12 \mathrm{~mm}$ $-12.5 \mathrm{~mm}$.

\section{Experimental work}

The tests were conducted in the Training Center at the University of Technology, Baghdad. A test was carried on the device BOGE shock Tester to be sure from the validity and accuracy of the measurements that can be obtained from it, Where device was maintained, reoperated and calibrated with the help of specialist engineers who are working in used laboratory .Theoretically we consider that the sinusoidal profile of 
the road is self similar and therefore can be modeled to smaller size by an eccentric cam (Fig.3). The tests were carried out in three stages to raise the suspension system of saloon car type (Mitsubishi saloon 1989 ) for the left wheel of the front axle. At each stage, the sprung length was determined by winding the wheel to press the sprung to change its length. Changing the length of the used sprung will control the frequencies that can be obtained at different speeds, where the joint points are accelerated from zero to maximum ( $\mathrm{a}=0$ to $\mathrm{a}=\max$ ). To determine the effect of the wheel speed and thee wavelength phase over the frequency range that can reveal the changes on the displacement and acceleration of the joint points, the device is designed so that during its operation gives an upward and downward acceleration throughout the movement of the wheel with a change in the wavelength amplitude, indicating the type of the road and its relationship with vehicle speed, features and characteristics of the suspension system. The following table shows the obtained results of the current work.

The accelerometer firmly mounted on timber and Perspex board was used to measure the effect of horizontal vibration s along the vehicle and vertically across the body and passengers

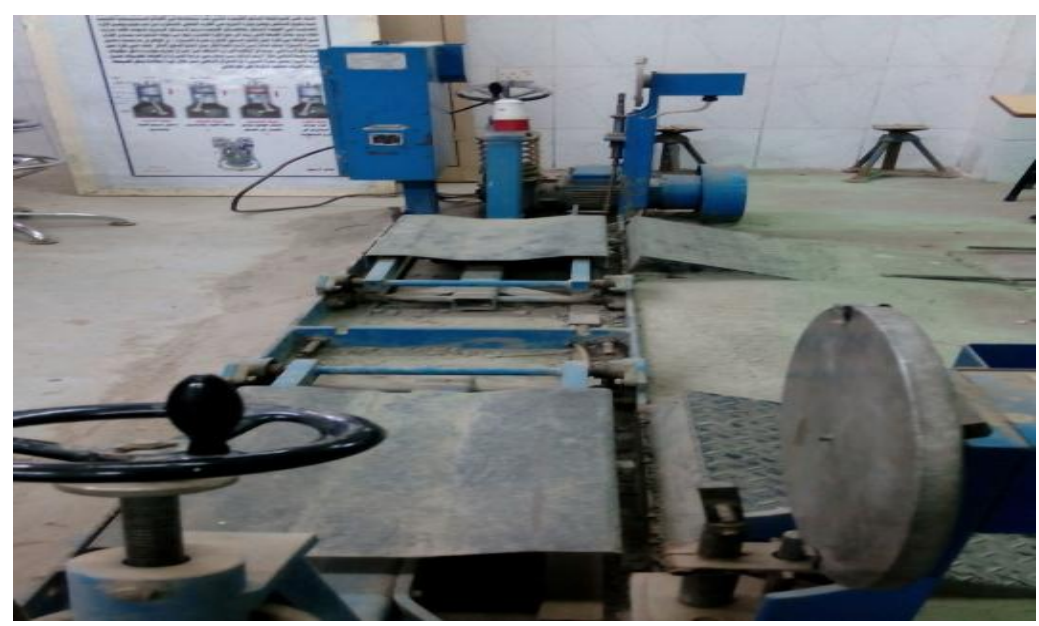

Figure 3. Experimental Setup

\section{Results and Discussion}

One of the greatest impacts on the mechanical parts of the vehicle is that of the speed of the vehicle at a different speed on the roads of poor quality, where it is found in the experiment and to test that the road contains irregular heights or bumps with a slow speed has the greatest impact on the connections and the structure of the vehicle and on the passenger to a degree that could lead to a break and stop it from working. The reason for this is the socalled dynamic loads generated by continuous vibrations caused by the roughness of the road. The movement on an uneven road leads to the creation of a reciprocal stirring with a force moving upward. As far as the forward parts of the vehicle are inclined, this force is tangential and vertical. On the axis of the wheel and to this compound involved two vectors, vertical and horizontal forces, causing Long wave frequency of the be calculated by the following equation: The result of this determination is to raise the front of the vehicle and make the steering process anxious, and also increases the amount of angle of torsion of the load system. The experiment was conducted on the vibration and shock measuring device located in the laboratories of the University of Technology / Baghdad, because it is not possible to conduct tests on the external roads directly because of the lack of means of testing and measurement and simulated the factors of the way through the device and calculate the angular speed of the wheel depending on the number of vibrations we get from the device During the time unit, it is also possible to represent the type of road through the decentralized cam located below the wheel to obtain the wavelength of the altitudes and frequencies that arise from it. Then the drawings were recorded on a digital panel through sensors connected to places in the structure and sprungs. Some mathematical equations were used to calculate test-related values.

Table 2. 1/4 - vehicle pattern data used for experiment vehicle

\begin{tabular}{|c|c|}
\hline Parameter & Value \\
\hline Ms & $325 \mathrm{~kg}$ \\
\hline Mus & $32.5 \mathrm{~kg}$ \\
\hline $\mathrm{Ks}$ & $22.22 \mathrm{kNm}-1$ \\
\hline $\mathrm{Kt}$ & $254.8 \mathrm{kNm}-1$ \\
\hline $\mathrm{Bs}$ & $2250 \mathrm{~kg} / \mathrm{s}$ \\
\hline $\mathrm{Bt}$ & $50 \mathrm{~kg} / \mathrm{s}$ \\
\hline
\end{tabular}


Table 3. Experimental values of $\omega$ and $F$ when speed various from $10-70 \mathrm{Km} / \mathrm{hr}$

\begin{tabular}{|c|c|c|}
\hline $\begin{array}{l}\text { Speed Km/hr } \\
\text { from } 10-80\end{array}$ & $\begin{array}{l}\text { Rotational speed } \\
\omega \mathrm{rad} / \mathrm{s}\end{array}$ & $\begin{array}{l}\text { Imbalance } \\
\text { force }(\mathrm{F}) \mathrm{KN}\end{array}$ \\
\hline 10 & 7.81 & 6.383 \\
\hline 20 & 15.62 & 25.53 \\
\hline 30 & 23.43 & 57.45 \\
\hline 40 & 31.24 & 102.1348 \\
\hline 50 & 39.05 & 159.585 \\
\hline 60 & 46.87 & 229.9 \\
\hline 70 & 54.68 & 312.9 \\
\hline
\end{tabular}

Table 4. Effect of stiffness on RR and $\boldsymbol{\delta}$

\begin{tabular}{|c|c|c|}
\hline $\begin{array}{l}\text { Suspension } \\
\text { stiffness Ks } \\
\text { KN }\end{array}$ & $\begin{array}{l}\text { Ride rate }(\mathrm{RR}) \\
\mathrm{N} / \mathrm{m}\end{array}$ & $\begin{array}{l}\text { Static deflection } \\
\boldsymbol{\delta}(\mathrm{m})\end{array}$ \\
\hline $20 \times 10^{3}$ & 18367.3 & 0.745 \\
\hline $25 \times 10^{3}$ & 22959 & 0.596 \\
\hline $30 \times 10^{3}$ & 27551 & 0.497 \\
\hline $40 \times 10^{3}$ & 36734.7 & 0.372 \\
\hline $50 \times 10^{3}$ & 45918.36 & 0.298 \\
\hline $60 \times 10^{3}$ & 55102 & 0.248 \\
\hline
\end{tabular}

$F_{i}=(m r) \omega^{2}$ imbalance force, $\mathrm{W} / \mathrm{Ks}$ is the static bending of suspension according to car weight. Figure (4) shows thee relationship between natural frequency to the static deflection. It is necessary to achieve a $1-2 \mathrm{~Hz}$ the static deflection falls between $0.2-0.3 \mathrm{~m}$

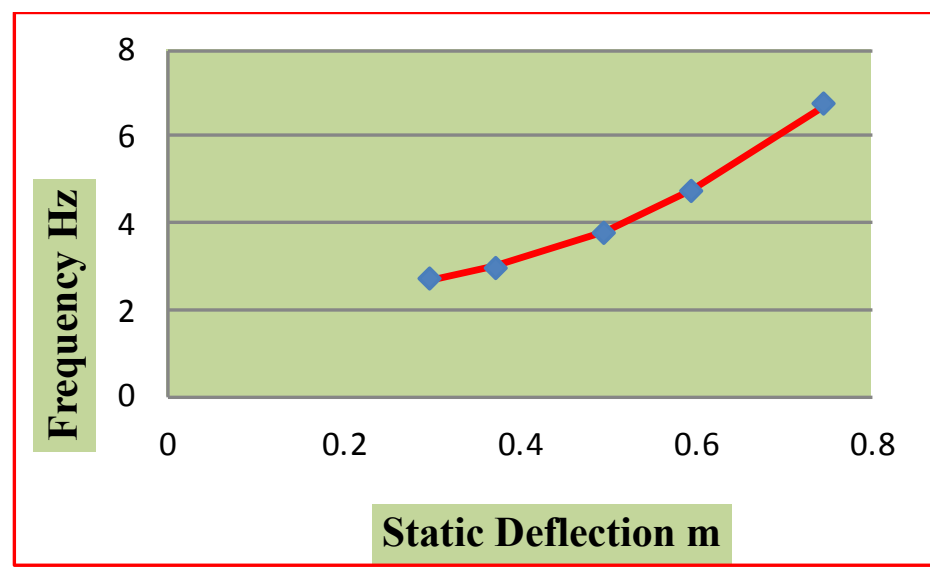

Figure 4. Relation between natural frequency and $\boldsymbol{\delta}$.

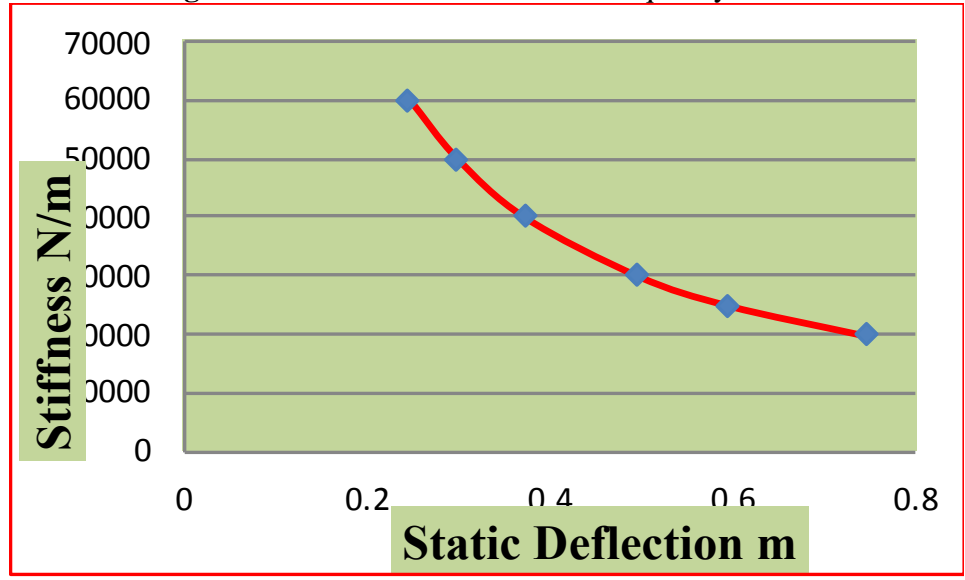

Figure 5. Suspension stiffness (Ks) versus static deflection 
Because the suspension sprung is in series with relatively stiff tire sprung, the suspension sprung dominate in promotion the ride rate hence, the suspension system natural frequency in the bounce mode [1] .To keeping natural frequency as low as possible, the road acceleration must be decrease to low frequency this mean the static deflection at the lest value as shown in fig. (3). And for good ride rate the damping ratio should be exist so as to absorb accelerate road bumps . Fig. (4) shows the effect of stiffness on damping ratio

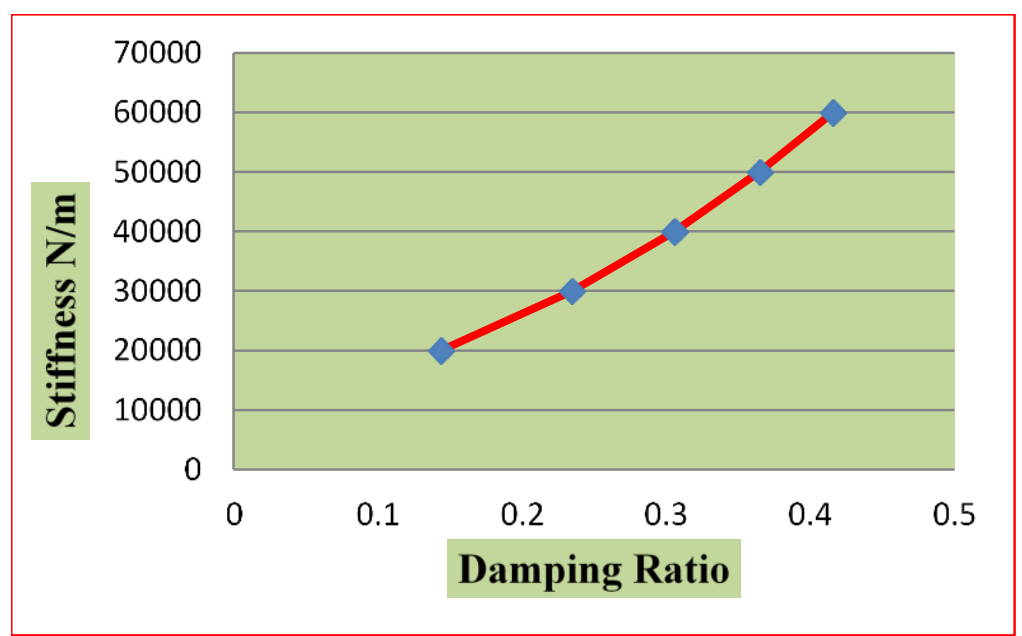

Figure 6. Relation between the damping ratio and the stiffness

\section{Conclusions}

The engineer's goal should generally be to elimination of all vibration in a vehicle. Even though this will never be possible in a motor vehicle, it does give direction to development effort yet there are two contrary phenomena that must be dealt with. First, the elimination of one vibration will always expose another lesser annoyances. This has been illustrated in past stories of making cars ride so well that the sound of the clock became annoyingly. Second, in the limit, elimination of all vibration is also undesirable, inasmuch as vibration are the source of road feel considered to be fundamental feedback to the driver of a motor vehicle.

\section{References}

[1] Tomas D.Gillespie , Fundamentals of Vehicle Dynamics ,publishe. SAE International, 1992.

[2] Holt, J.E., and D. Schoorl, "A Theoretical and Experimental Analysis of Suspension and Road Profile on Bruising in Multillayered Apple Packs, J. Agric. Engng. Res. 31 (1985) 297-308.

[3] K. Vursavus and F. Ozguven, Determining the Effects of Vibration Parameters and

[4] Packaging Method on Mechanical Damage in Golden Delicious Apples, Turk. J Agric, 28 (2004) 311- 320.

[5] O. Gundogdu, O., "Optimal seat and suspension design for a quarter car with driver model using genetic algorithms, International Journal of Industrial Ergonomics, 37(4), (2007), 327-332.

[6] A. Agharkakli, G. S. Sabet, A. Barouz, Simulation and Analysis of Passive and Active Suspension System Using Quarter Car Model for Different Road Profile, International Journal of
Engineering Trends and Technology, 3(5), (2012), 636-644.

[7] P.Y. Zhu, J.P. Hessling, D.S. Liu, Optimal road hump for comfortable speed reduction, Fourth International Symposium on Precision Mechanical Measurements, Proc. of SPIE Vol. 7130, 71304L .

[8] Satish B. Purohit, S.R Lapalikar ,'Effect of road and curve generated by wheel on the performance of a shock absorber of a motorcycle", Indian gournal of science and Technology, Vol. 4 No.5 May 20111.

[9] Griffin, M.J., Handbook of Human Vibration. (1996), Academic press, London Publication, ISBN-10: 0123030412. 